\title{
DC Motor Control Using Laboratory Virtual Instrumentation Engineering Workbench
}

\author{
Bustanul Arifin ${ }^{1)}$, Eka Nuryanto Budisusila ${ }^{2)}$ \\ ${ }^{1,2}$ Program Studi Teknik Elektro FTI Universitas Islam Sultan Agung \\ Email Korespondensi : "bustanul@unissula.ac.id
}

Received: 27 November 2019; Accepted : 9 April 2020; Published : 1 November 2020

\begin{abstract}
ABSTRAK
Motor mempunyai peranan penting dalam kehidupan sehari-hari. Baik digunakan dalam skala rumahan maupun di dunia industri. Untuk mengatur motor ini diperlukan suatu sistem pengendalian yang baik. Laboratory Virtual Instrumentation Engineering Workbench yang disingkat dengan LabVIEW didefinisikan sebagai suatu software sistem engineering yang digunakan untuk kebutuhan pengujian, pengukuran, dan pengendalian secara cepat pada pengaksesan hardware yang didalamnya terdapat data-data yang dibutuhkan. LabVIEW menggunakan bahasa pemrograman berbasis grafis atau blok diagram sementara bahasa pemrograman lainnya menggunakan basis text. Penelitian ini bertujuan untuk mendapatkan suatu nilai pengendalian motor DC dan pembahasannya dengan menggunakan LabVIEW. Metode yang digunakan dalam penelitian ini adalah merangkai hardware motor DC dengan driver dilanjutkan dengan menghubungkannya ke sebuah pengendali board myRIO 1900. Dengan memberikan variasi frekuensi dan duty cycle, hasil arus dan tegangan serta putaran didapatkan untuk mengetahui pengaruhnya. Hasil penelitian ini menunjukkan bahwa dengan memberikan duty cycle lebih dari 50\% didapatkan arus dan tegangan serta putaran motor yang linear dan membentuk garis yang mendatar. Frekuensi $100 \mathrm{~Hz}$ merupakan frekuensi paling baik yang dapat menghasilkan putaran motor tertinggi.
\end{abstract}

Kata kunci: motor dc, kendali, LabVIEW

\begin{abstract}
Motor has an important role in everyday life. Both are used on a home scale and in the industrial world. To regulate a motor, a good control system is needed. Laboratory Virtual Instrumentation Engineering Workbench abbreviated as LabVIEW is defined as a system engineering software that is used for the needs of testing, measuring, and controlling quickly on accessing hardware in which there is data needed. LabVIEW uses a graphics-based programming language or block diagram while other programming languages use a text base. This study aims to obtain a value of DC motor control. The method used in this research is to assemble the DC motor hardware with the driver followed by connecting it to a myRIO 1900 board controller. By providing variations in frequency and duty cycle, the results of current and voltage and rotation are obtained to determine its effect. The results of this study indicate that by giving a duty cycle of more than 50\%, current and voltage are obtained and the motor rotation is linear and forms a horizontal line. The 100 $\mathrm{Hz}$ frequency is the best frequency that can produce the highest motor rotation.
\end{abstract}

Keyword: DC motor, control, LabVIEW.

\section{PENGANTAR}

Dengan semakin majunya komputer digital yang merupakan suatu sarana pengendali maka salah satu bidang ilmu teknik yang perkembangannya sangat pesat adalah sistem kendali. Yang dimaksud komputer digital di sini adalah teknologi mikroprosesor atau mikrokontroler yang digunakan untuk pemrograman sistem kendali. Sistem kendali sering juga disebut dengan kendali otomatik, sistem pengaturan, teknik pengaturan, sistem kendali ataupun sistem servo. Istilah-istilah ini pada dasarnya disesuaikan dengan bidang penerapannya yaitu pada bidang industri, mesin-mesin, perlatan listrik ataupun elektronik, penerbangan, ataupun penggunaan pada bidang lainnya. Pemahaman konsep pada bidang ini memerlukan pengetahuan matematika dan fisika yang lebih tinggi seperti pada persamaan linear diferensial dan transformasi laplace.

Untuk analisis dan perancangan sistem kendali, sistem fisis harus dibuat model fisisnya. Model fisis ini harus dapat menggambarkan karakteristik dinamis suatu sistem secara memadai. Berdasarkan model fisis diturunkan model matematisnya. Model matematis diartikan sebagai hubungan matematik yang menghubungkan keluaran sistem dengan masukannya. Suatu sistem yang memiliki model matematis sama tidak selalu menggambarkan model fisis yang sama [1].

Motor arus searah banyak digunakan secara luas di bidang industri pada berbagai aplikasi. Motor arus searah ini mempunyai karakteristik dimana kecepatan motor arus searah ini dapat diatur. Pengaturan 
kecepatan motor arus searah ini dilakukan karena ada banyak gangguan yang mungkin terjadi seperti kehilangan beban secara tiba-tiba sehingga kecepatan motor arus searah menjadi lebih tinggi. Gangguan lain adalah adanya perubahan nilai resistansi pada komutator motor arus searah dan lain sebagainya. Analisa yang dilakukan dapat meliputi analisa performansi dalam domain waktu, analisa performansi dalam domain frekuensi, analisa kestabilan dan kekokohan dengan menggunakan berbagai perangkat lunak.

Perangkat lunak atau software yang digunakan untuk keperluan pengendalian meliputi berbagai bentuk. Mulai dari bahasa pemrograman C, visual Basic, delphi, Matlab, dan lain sebagainya. Sebagian besar bahasa pemrograman yang digunakan adalah berbasis text. Bahasa-bahasa pemrograman tersebut sudah sangat umum digunakan dalam berbagai aplikasi pengendalian. Salah satu platform bahasa pemrograman yang berbasis selain text adalah berbahasa pemrograman berdasarkan grafis. Pemrograman ini menggunakan software Laboratory Virtual Instrumentation Engineering Workbench. Bahasa ini menarik untuk dikembangkan karena mempunyai beberapa keunggulan diantaranya adalah dapat mengurangi peralatanperalatan instrumentasi yang digunakan untuk melakukan pengukuran. Hal ini dapat dimengerti karena dasar dari bahasa ini adalah berbentuk grafis [2], [3].

Penelitian untuk pengendalian motor DC dengan PWM telah dilakukan dengan menggunakan mikrokontroler AVR yang dihubungkan dengan komputer secara komunikasi serial [4]. Untuk mengendalikan motor perlu memperkuat sinyal output dari mikrokontroler dengan cara menggunakan IC driver modul-bridge L293D. Sinyal PWM dihasilkan dari proses pengaturan timer pada mikrokontroler dan dari driver motor. Hasil sinyal PWM dari mikrokontroler lebih bagus dibandingkan dengan hasil dari driver motor. Nilai PWM tidak linear dengan hasil keluaran dikarenakan karakteristik IC L293D yang mempunyai drop tegangan senilai 1,8 sampai dengan 3,2 volt. Dengan nilai PWM, penelitian [5] mengatur putaran motor DC berdasarkan suhu yang didapatkan dari sensor PTC. Pengontrol yang digunakan adalah Arduino Mega 2560 .

Arduino Uno digunakan untuk menjaga kecepatan motor DC yang telah diberi beban secara berubah-ubah agar tetap pada setpoint yang diinginkan [6]. Penelitian ini memberikan variasi power suplai dan juga variasi beban. Hasil yang didapatkan adalah ketika motor mendapatkan beban yang besar maka nilai PWM harus ditingkatkan agar tercapai pada nilai setpointnya. Penelitian yang hampir sama juga dilakukan dengan menggunakan mikrokontroler PIC 16F877A [7]. Mikrokontroler dapat mudah untuk membantu mempertahankan nilai setpoint dengan variasi beban.

Pegatur kecepatan motor dengan PWM dilakukan pada penelitian yang diimplementasikan pada teknologi robotik [8]. Cara yang digunakan adalah mengatur timer pada mikrokontroler AtTiny 2313 dan Atmega 128. Duty cycle yang paling sesuai untuk kondisi robot berjalan pada daerah datar adalah $78 \%$ dan ketika berada di daerah tanjakan bernilai 41\%. Pengatur kecepatan motor juga dilakukan dengan menggunakan mikrokontroler Atmega 16 yang dihubungkan dengan sebuah personal komputer [9]. Untuk mendrive motor DC, empat kanal monolitik driver digunakan dengan dioda clamps.

Berdasarkan penelitian-penelitian sebelumnya, belum ditemukan penelitian yang menggunakan LabVIEW dan board myRIO untuk pengaturan kecepatan motor dengan PWM. Oleh karena itu dilakukanlah penelitian yang berbasis dengan bahasa pemrograman yang berbentuk grafis.

Diskripsi matematik dari karakteristik dinamik suatu sistem disebut model matematis. Langkah pertama dalam analisis suatu sistem dinamik adalah menurunkan modelnya. Model dapat disajikan dalam beberapa bentuk yang berbeda. Setelah suatu model matematis suatu sistem diperoleh, berbagai perangkat analitik dan komputer dapat digunak

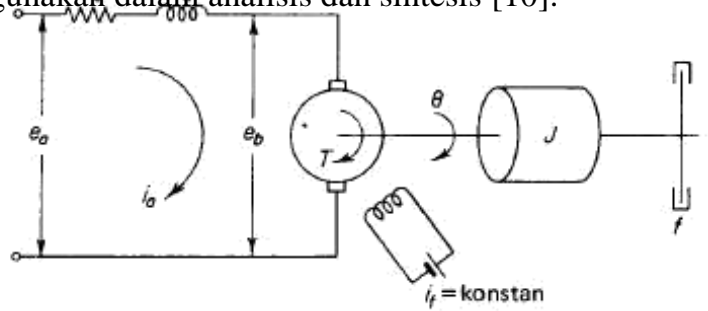

Gambar 1. Diagram skematik motor DC

Gambar 1 memperlihatkan diagram skematik motor DC [11]. Model motor DC dapat didapatkan berdasarkan persamaan:

$$
\begin{gathered}
i_{a} R_{a}+L_{a} \frac{d i_{a}}{d t}+K_{b} \frac{d \theta}{d t}=V_{a} \\
J \frac{d^{2} \theta}{d t^{2}}+B \frac{d \theta}{d t}=K_{t} i_{q}
\end{gathered}
$$




\section{Dengan:}

$\mathrm{J}=$ Momen inesrsia motor $\left(\mathrm{kg} \mathrm{m}^{2}\right)$

$\mathrm{B}=$ Koefisien friksi motor $(\mathrm{Nm} / \mathrm{rad} / \mathrm{sec})$

$\mathrm{K}_{\mathrm{t}}=$ Konstanta Torsi motor $(\mathrm{Nm} / \mathrm{A})$

$\mathrm{K}_{\mathrm{b}}=$ Konstanta motor back emf $(\mathrm{V} / \mathrm{rad} / \mathrm{sec})$

$\mathrm{i}_{\mathrm{a}}=\operatorname{arus} \operatorname{armatur}(\mathrm{A})$

$\mathrm{V}_{\mathrm{a}}=$ Tegangan armatur $(\mathrm{V})$

$\mathrm{R}_{\mathrm{a}}=$ Resistansi armatur (ohm)

$\mathrm{L}_{\mathrm{a}}=$ Induktansi armatur $(\mathrm{mH})$

Model ruang keadaan (state space) dari motor DC diperoleh dengan pemilihan ia, $\omega$, dan $\theta$ sebagai variabel keadaan.

Pensubstitusian ke variabel keadaan, sehingga diperoleh persamaan:

$$
\begin{gathered}
x_{1}=i_{1} ; \quad x_{2}=\omega=\frac{d \theta}{d t} ; x_{3}=\theta ; u=V_{a} \\
y_{1}=i_{a} ; y_{2}=\omega=\frac{d \theta}{d t} ; y_{3}=\theta
\end{gathered}
$$

$$
\begin{aligned}
& \dot{x}_{1}=-\frac{R_{a}}{L_{a}} \cdot x_{1}-\frac{K_{b} x_{2}}{L_{a}}+\frac{u}{L_{a}} \\
& \dot{x}_{2}=\frac{K_{t}}{J} \cdot x_{1}-\frac{B x_{2}}{J} \\
& \dot{x}_{3}=x_{2}
\end{aligned}
$$

Persamaan tersebut disusun menjadi bentuk matriks sehingga menjadi

$$
\left[\begin{array}{l}
\dot{x}_{1} \\
\dot{x}_{2} \\
\dot{x}_{3}
\end{array}\right]=\left[\begin{array}{ccc}
-\frac{R_{a}}{L_{a}} & -\frac{K_{b}}{L_{a}} & 0 \\
\frac{K_{t}}{J} & -\frac{B}{J} & 0 \\
0 & 1 & 0
\end{array}\right]\left[\begin{array}{l}
x_{1} \\
x_{2} \\
x_{3}
\end{array}\right]+\left[\begin{array}{c}
\frac{1}{L_{a}} \\
0 \\
0
\end{array}\right][u]
$$

Variabel ouput yang diinginkan $\mathrm{i}_{\mathrm{a}}, \omega$, dan $\theta$ dinyatakan dalama notas $\mathrm{y}_{1}, \mathrm{y}_{2}$, dan $\mathrm{y}_{3}$.

$$
y_{1}=i_{a} ; y_{2}=\omega=\frac{d \theta}{d t} ; y_{3}=\theta
$$

Hubungan output terhadap variabel keadaan didapatkan:

$$
y_{1}=x_{1} ; y_{2}=x_{2} ; y_{3}=x_{3}
$$

Maka persamaan output dengan bentuk matriks adalah

$$
\left[\begin{array}{l}
y_{1} \\
y_{2} \\
y_{3}
\end{array}\right]=\left[\begin{array}{lll}
1 & 0 & 0 \\
0 & 1 & 0 \\
0 & 0 & 1
\end{array}\right]\left[\begin{array}{l}
x_{1} \\
x_{2} \\
x_{3}
\end{array}\right]
$$

Transfer function:

$\mathrm{H}(\mathrm{S})=\mathrm{C}(\mathrm{SI}-\mathrm{A})^{-1} \mathrm{~B}+\mathrm{D}$

Dari persamaan (6) dan persamaan (7) didapatkan:

$$
\begin{array}{cc}
A=\left[\begin{array}{ccc}
-\frac{R_{a}}{L_{a}} & -\frac{K_{b}}{L_{a}} & 0 \\
\frac{K_{t}}{J} & -\frac{B}{J} & 0 \\
0 & 1 & 0
\end{array}\right] ; \quad B=\left[\begin{array}{c}
1 \\
L_{a} \\
0 \\
0
\end{array}\right] ; \\
C=\left[\begin{array}{ccc}
1 & 0 & 0 \\
0 & 1 & 0 \\
0 & 0 & 1
\end{array}\right] ; & D=0
\end{array}
$$


Dengan substitusi nilai A, B, C, dan D ke dalam persamaan (8), transfer function persamaan motor menjadi

$$
H_{s}=\frac{\dot{\theta}(s)}{V_{a}(s)}=\frac{K_{t}}{S^{2} J L_{a}+S\left(B L_{a}+J R_{a}\right)+\left(B R_{a}+K_{t} K_{b}\right)}
$$

\section{METODE PENELITIAN}

Untuk dapat melakukan penelitian yang baik diperlukan studi pustaka yang mendalam berkaitan dengan materi. Oleh karena itu diperlukan pendalaman materi tentang kendali dan pengendalian motor DC serta software LabVIEW secara mendalam. Pendalaman materi berupa teori-teori maupun penelitianpenelitian lain yang membahas mengenai materi tersebut. Perancangan sistem dibuat berdasarkan keadaan nyata di lapangan bahwa motor DC banyak sekali digunakan dalam kehidupan sehari-hari. Motor ini digunakan baik dalam skala rumahan maupun didalam skala yang lebih besar yaitu dunia industri. Untuk dapat menggunakannya dengan baik diperlukan suatu pengendalian yang tepat. Pengendalian yang diajukan dalam penelitian ini adalah pengendalian motor DC menggunakan program LabVIEW. Progam ini menggunakan desain grafis, berbeda dengan program-program lain yang menggunakan test sebagai bahasa pemrogamannya. Dengan menggunakan program LabVIEW, motor DC dihubungkan dengan board myRIO 1900 yang telah dilengkapi dengan sebuah driver motor untuk memberi power pada motor DC. Sinyal PWM digunakan untuk mengaktifkan motor DC dengan variasi duty cycle dann variasi frekuensi. Tahapan analisa dan pembahasan akan membahas sistem kendali yang didapatkan dengan mencari kelebihan dan kelemahannya. Sistem ini akan diuji unjuk kerjanya dalam melaksanakan fungsinya sebagai pengendali motor DC. Hasil-hasil penting akan dirangkum dalam kesimpulan yang bermanfaat dan saran-saran untuk pengembangan sistem ini juga disampaikan dibagian ini. Diagram alir metode penelitian yang dilakukan diperlihatkan pada Gambar 2.

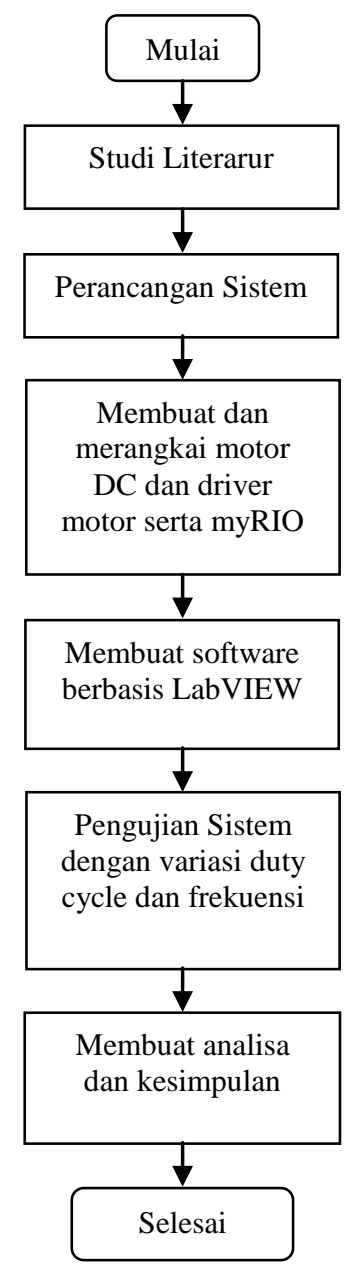

Gambar 2. Diagram alir metode penelitian 
Pengendalian motor DC ini menggunakan beberapa device untuk merealisasikannya. Device tersebut antar lain myRIO 1900 yang dijalankan dengan software LabVIEW keluaran National Instruments, driver motor, dan motor DC. Motor DC yang digunakan IG220019X00015R dengan tegangan maksimum 12 V 15.000 RPM, arus maksimal tanpa beban $200 \mathrm{~mA}$, kecepatan tanpa beban $789 \mathrm{rpm} \pm 15 \%$, resistansi coil 5 $\Omega$, dan motor ini dilengkapi dengan gear reduksi dengan rasio $1 / 19,225$. Motor ini juga dilengkapi dengan encoder untuk mengetahui jumlah putaran per menit (rpm). Motor yang digunakan mempunyai kabel penghubung sebanyak enam, yaitu kabel warna hitam untuk tegangan negatif motor, kabel merah untuk tegangan positif motor, kabel coklat untuk Vec sensor hall, kabel hijau terhubung ke ground sensor hall, kabel biru untuk Vout A sensor hall, dan kabel ungu (purple) terhubung Vout B sensor hall.

Untuk driver motor digunakan sebuah motor adapter yang akan dihubungkan dengan pemroses myRIO 1900. Motor adapter ini terdiri atas beberapa rangkaian utama yaitu IC pengontrol hot-swap efisiensi tinggi pembatas daya (High-efficiency Power-limiting Hot-swap controller) TPS24711 dan driver motor PWM jembatan penuh (Full-bridge PWM Motor Driver) A4973. Power manager TI TPS24711 membutuhkan power suplai untuk motor yang digunakan. Sesuai dengan data sheet yang ada, tegangan yang dapat diterima adalah 6 volt sampai dengan 16 volt DC. Pada penelitian ini dipilih tegangan 9 volt dengan pertimbangan untuk keamanan dari rangkaian. Disamping itu kerja motor DC juga berpengaruh dengan tegangan yang diumpankan ke TPS24711. Input dan output motor adapter ini dilengkapi dengan konektor MXP yaitu myRIO Expantion Port. Konektor MXP ini dapat dihubungkan ke MXP-A dan juga dapat dihubungkan ke MXP-B pada modul myRIO. Tegangan +5 volt dihubungkan dengan suplai daya motor encoder dan juga pengendali PWM motor A4973. Power manager mengirimkan sinyal ke driver motor untuk kemudian dikirimkan berupa sinyal ke motor DC. kecepatan motor diatur dengan sinyal PWM yang didapatkan dari myRIO, begitu juga dengan arah motor $(C W=$ clock wise dan $C C W=$ contra clock wise $)$.

Untuk dapat mengendalikan motor dengan sinyal PWM, penelitian ini menggunakan software LabVIEW. Software ini digunakan untuk memprogram device myRIO 1900 yang akan terhubung dengan driver dan motor DC. Untuk mengawali program yang dibuat device myRIO harus dihubungkan dengan komputer yang telah diinstall LabVIEW. Channel yang dipilih adalah channel A sehingga motor driver akan dihubungkan ke myRIO port MXP-A pada pin 27. Pengaturan frekuensi dan duty cycle dipilih pada posisi Set using input to Express VI karena penelitian ini bertujuan untuk mendapatkan hasil dari berbagai variasi input frekuensi dan duty cycle. Encoder merupakan data yang diperoleh dari motor DC yang dilengkapi oleh sensor putaran motor. Data ini berfungsi untuk mengetahui RPM yang dihasilkan dari berbagai variasi frekuensi dan duty cycle. Output encoder LabVIEW ini dihubungkan dengan waveform graph agar dapat diketahui bentuk sinyal yang dihasilkan. Untuk memanggil waveform graph dengan cara mengklik kanan Front Panel LabVIEW, Graph, Waveform Graph. Pin 23 pada MXP-A dihubungkan dengan driver motor yang akan dikendalikan. Hasil desain diagram blok keseluruhan pengendali motor DC dengan PWM menggunakan LabVIEW ditunjukkan pada Gambar 3.

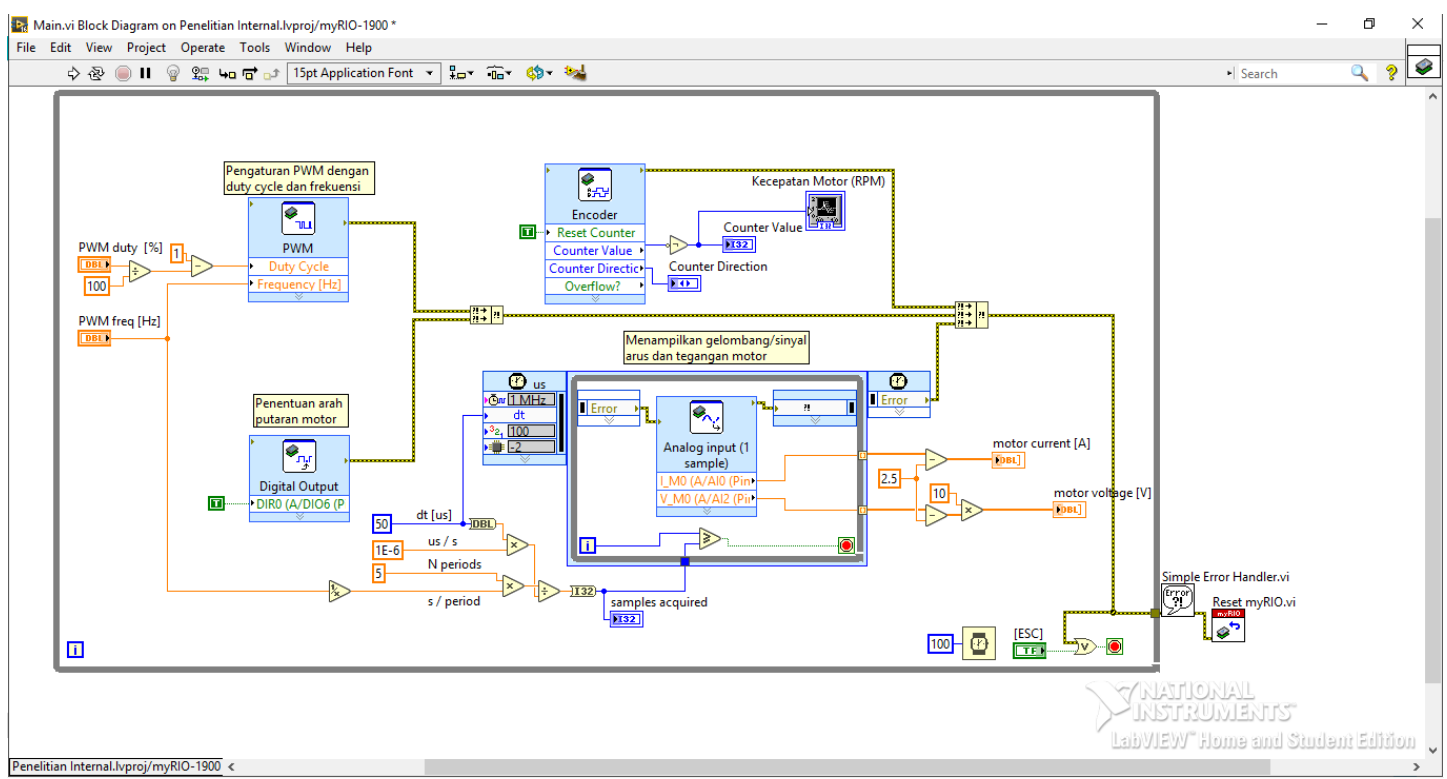

Gambar 3. Tampilan diagram blok sistem 


\section{HASIL DAN PEMBAHASAN}

Setelah rangkaian motor, motor adapter, dan myRIO telah lengkap maka program yang telah dibuat di LabVIEW didownload ke board myRIO. Pada penelitian ini dilakukan berbagai variasi duty cycle mulai dari yang terendah yaitu $10 \%$ hingga tertinggi $100 \%$. Kenaikan setiap variasi adalah dengan memberi penambahan nilai 10\%. Untuk frekuensi dimulai dari frekuensi $100 \mathrm{~Hz}$ hingga frekuensi $1000 \mathrm{~Hz}$. Penambahan $100 \mathrm{~Hz}$ dilakukan untuk memberikan variasi pengukuran penelitian ini.

Hasil rata-rata keseluruhan duty cycle yang dicoba pada penelitian ini dirangkum dalam Tabel 1. Gambar 4 menunjukkan grafik hasil keseluruhan nilai RPM yang diperoleh. Dari gambar dapat dianalisa bahwa mulai dari PWM yang mempunyai nilai duty cycle 50\% penurunan nilai RPM terjadi tetapi mengalami pengurangan yang sedikit. Penurunan nilai RPM tidak terlalu signifikan karena dari grafik yang diperoleh gambarnya hampir mendatar.

Tabel 1. Hasil keseluruhan rata-rata RPM

\begin{tabular}{ccccccccccc}
\hline $\begin{array}{c}\text { Frekuensi } \\
(\mathbf{H z})\end{array}$ & $\mathbf{1 0}$ & $\mathbf{2 0}$ & $\mathbf{3 0}$ & $\mathbf{4 0}$ & $\mathbf{5 0}$ & $\mathbf{6 0}$ & $\mathbf{7 0}$ & $\mathbf{8 0}$ & $\mathbf{9 0}$ & $\mathbf{1 0 0}$ \\
\hline 100 & 31.4 & 132 & 168.8 & 187 & 196 & 199.4 & 199.4 & 209 & 213.4 & 215.8 \\
200 & 11.6 & 120.2 & 161.8 & 182.4 & 192.6 & 196.8 & 198.2 & 207.6 & 212.8 & 215.8 \\
300 & 0 & 102.6 & 154.2 & 178.8 & 189.8 & 195 & 197.2 & 206.8 & 211.2 & 215.8 \\
400 & 0 & 88.6 & 146.4 & 173.2 & 187 & 193.6 & 196.4 & 205.6 & 210.4 & 215.6 \\
500 & 0 & 78 & 139.2 & 168.6 & 183.8 & 191 & 194.8 & 204.4 & 209.6 & 215.4 \\
600 & 0 & 64.2 & 131 & 162.8 & 180 & 188.4 & 194.4 & 203.8 & 208.8 & 215.2 \\
700 & 0 & 56.4 & 123.4 & 158.4 & 177 & 185.6 & 193 & 202.2 & 207.8 & 215.2 \\
800 & 0 & 46.2 & 117 & 153.4 & 173.8 & 183.6 & 191 & 201 & 206.8 & 215.2 \\
900 & 0 & 37.8 & 110.4 & 149.8 & 170.2 & 180.6 & 189.6 & 199.8 & 205.4 & 215 \\
1000 & 0 & 32.4 & 104.8 & 146 & 168 & 178.4 & 188 & 198.8 & 203.4 & 214.6 \\
\hline
\end{tabular}

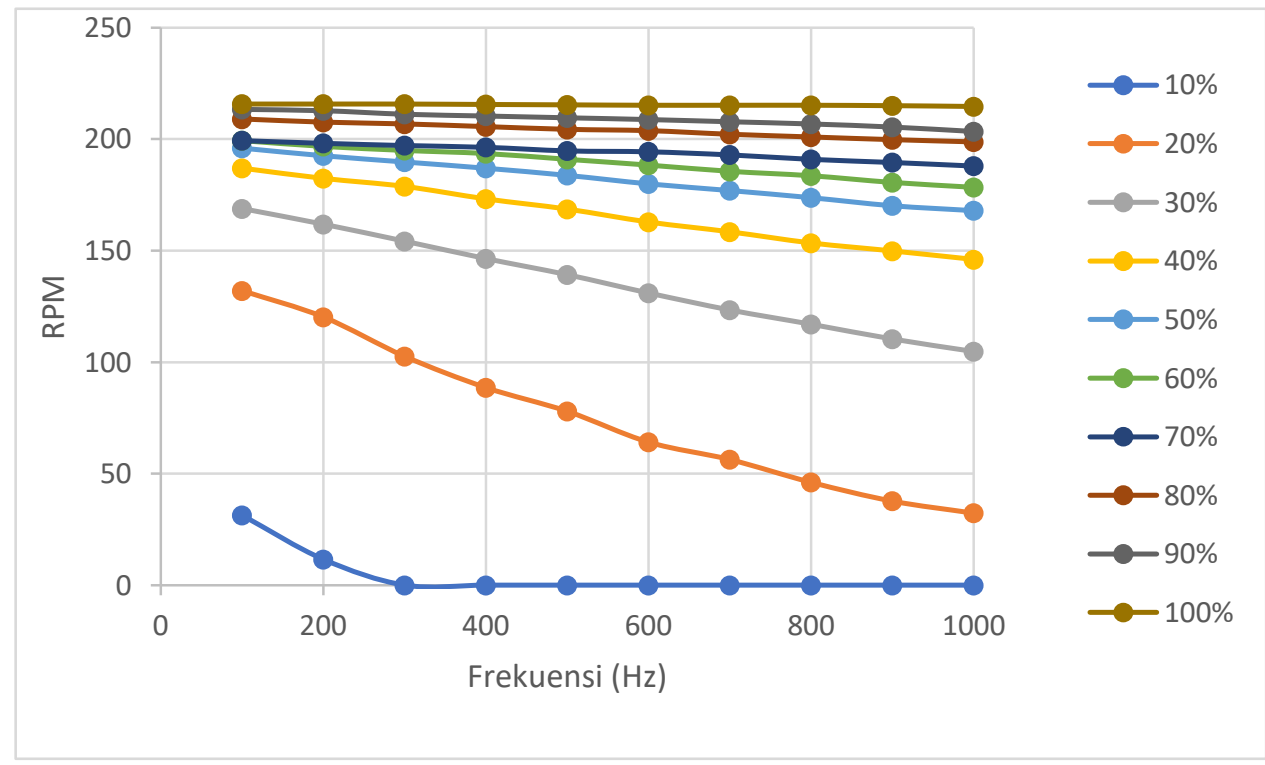

Gambar 4. Grafik hubungan frekuensi, duty cycle, dan RPM motor

Setelah mengetahui jumlah putaran motor per menit atau yang sering disebut dengan RPM, penelitian selanjutnya adalah menguji bentuk sinyal/gelombang yang terjadi pada motor DC. Dengan tampilan LabVIEW memungkinkan untuk mendapatkan sinyal arus dan tegangan dalam layar monitor komputer.

Pengujian ini dilakukan dengan tiga variasi setiap duty cycle yang dikenakan ke motor DC. Ketiga 
frekeunsi tersebut adalah dengan nilai $100 \mathrm{~Hz}, 500 \mathrm{~Hz}$, dan $1000 \mathrm{~Hz}$. Pada duty cycle $10 \%$ dengan frekuensi $100 \mathrm{~Hz}$, arus dan tegangan mempunyai amplitudo yang tinggi walaupun dengan lebar pulsa yang sangat sempit seperti tampak pada Gambar 5a. Hal ini menyebabkan motor masih mampu berputar walaupun dengan kecepatan rendah. Gambar 5b memperlihatkan bentuk sinyal pada saat mempunyai duty cycle 50\% diberi frekuensi $100 \mathrm{~Hz}$, lebih bagus dan mirip dengan sinyal persegi dibandingkan dengan sinyal PWM dengan frekuensi yang lebih tinggi. Pada kondisi ini terlihat ripple terjadi di atas maupun dibagian bawah sinyal. Gambar 5c merupakan hasil sinyal yang diperoleh ketika motor diberi sinyal PWM dengan duty cycle $100 \%$. Tampak pada gambar bahwa sinyal kondisi rendah sudah tidak ada lagi. Walaupun masih ada rippleripple kecil, tetapi sinyal hampir mendekati garis lurus mencapai puncak tegangan $9 \mathrm{~V}$.

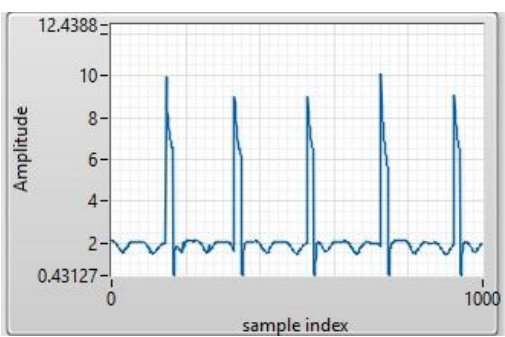

a)

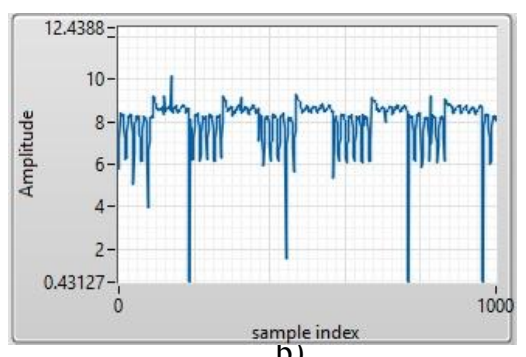

b)

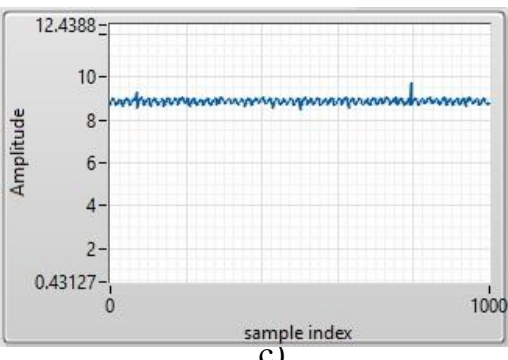

C)

Gambar 5. Bentuk sinyal dengan frekuensi $100 \mathrm{~Hz}$

a) duty cycle $10 \%$ b) duty cycle $50 \%$ c) duty cycle $100 \%$

Pulse Width Modulation (PWM) adalah salah satu cara yang efisien untuk dapat mengendalikan motor DC. Hal ini dikarenakan motor dapat dikontrol dengan kehilangan daya yang sedikit secara signifikan daripada dengan menggunakan pembatasan linear yang kontinu. Dalam sebuah rangkaian, beban resistif akan mempunyai sebuah arus yang proporsional dengan PWM. Motor DC adalah lebih kompleks dari sebuah beban resistif, motor dapat terdiri atas sebuah induktansi dan ketika motor berputar akan menghasilkan sebuah EMF (Electro Magnetic Force) balik. Faktor-faktor inilah yang menyebabkan PWM tidak selalu linear, frekuensi PWM (tidak hanya cukup pada duty cycle) secara aktual cukup signifikan untuk menjadi parameter output.

Ketika motor pada keadaan diam (atau pada kecepatan yang sangat rendah), maka tidak ada EMF balik (atau sangat kecil) dan rangkaian menjadi sederhana. Pada situsasi ini, arus dibatasi oleh resistansi dari kumparan dan induktansi koil. Sebagai tambahan, jika motor beroperasi dari sumber DC yang terbatas, bukan PWM, maka arus akan ditentukan hanya oleh resistansi sebagai induktansi bukan dari sebuah impedansi dengan sebuah sumber yang konstan.

Ketika sebuah tegangan diaplikasikan pada rangkaian induktansi L secara perlahan arus akan mengalami kenaikan, ini terjadi karena inductor menghasilkan sebuah EMF balik yang menghambat aliran arus yang melaluinya. Ini mencegah arus (dan kemudian tegangan melalui resistor) dari kenaikan atau penurunan yang terlalu cepat daripada konstanta waktu dari rangkaian. Semua rangkaian seri RL mempunyai konstanta waktu $\tau=\mathrm{L} / \mathrm{R}$.

Sebagai hasilnya, ketika power supply diaktifkan, arus tidak akan serta merta menjadi naik ke nilai steady-state dengan nilai V/R. Kenaikan membutuhkan beberapa waktu-konstanta untuk menjadi lengkap. Ketika menggunakan PWM untuk mengendalikan motor DC, situasi ini berulang setiap periode PWM. Jika beban hanya terdiri dari resisteif, frekuensi PWM tidak akan berpengaruh, tetapi karena rangkaian ini adalah rangkaian RL maka kenaikan arus dibatasi oleh induktansi. Oleh karena itu, sinyal PWM yang menggunakan frekuensi tinggi akan mengurangi waktu dalam kenaikan arus.

Penggunaan software LabVIEW dan hardware myRIO 1900 memberi keuntungan dibandingkan dengan menggunakan software dan hardware lain. Keunggulan tersebut adalah hasil pengukuran serta bentuk kurva yang diperlukan dapat ditampilkan secara langsung di komputer tanpa adanya perangkat tambahan lagi.

\section{KESIMPULAN}

Dengan menggunakan LabVIEW dapat dihasilkan pengendalian motor DC yang berbasis sinyal PWM. Pengendalian dengan PWM mempunyai dua parameter penting yaitu frekuensi dan duty cycle. Berdasarkan penelitian yang dilakukan, pada duty cycle yang sama semakin tinggi frekuensi yang digunakan maka tegangan dan arus semakin kecil. Hal ini berbanding lurus dengan kecepatan putaran motor sehingga menyebabkan menurun juga putarannya. Frekuensi yang paling baik menghasilkan putaran motor tertinggi berada pada nilai $100 \mathrm{~Hz}$. Putaran motor membentuk suatu garis linier yang mendatar pada nilai duty cycle di atas $50 \%$.

Peluang penelitian lanjutan adalah dengan memperluas variasi frekuensi dan duty cycle. Dengan menggunakan frekuensi di bawah dan di atas yang telah digunakan untuk mengetahui pada kondisi mana 
motor dapat menghasilkan putaran yang maksimal dan minimal. Begitu juga dengan penerapan variasi duty cycle yang lebih kecil range kenaikannya.

\section{DAFTAR PUSTAKA}

[1] H. Di. Laksono, Sistem Kendali dengan PID. Yogyakarta: Graha Ilmu, 2015.

[2] D. Artanto, Interface, Sensor, dan Aktuator Menggunakan Proteus, Arduino, dan LabVIEW. Yogyakarta: Deeppublish, 2017.

[3] D. Artanto, Interaksi Arduino dan LabVIEW. Jakarta: PT.Elex Media Komputindo, 2012.

[4] Baharuddin, R. S. Sadjad, and M. Tola, "Sistem kendali Kecepatan Motor DC Berbasis PWM ( Pulse Width Modulation )," Universitas Hasanuddin, 2012.

[5] S. Andrianto, "Sistem Pengendali Kecepatan Putaran Motor DC Berdasarkan PWM berbasis Arduino Mega," Palembang: Politeknik Negeri Sriiwjaya, 2016.

[6] B. H. Soelaiman, "Pengendalian Motor DC Menggunakan Pulse Width Modulation (PWM)," 2014.

[7] R. S. . Katke S.P, "Speed Control of DC Motor Using Microcontroler," Int. J. Adv. Technol. Eng. Sci., vol. 02, no. 12, p. 6, 2015.

[8] S. Arifin and A. Fathoni, "Pemanfaatan Pulse Width Modulation untuk Mengantrol Motor (Studi Kasus Robot Otomatis Dua Deviana) DEVIANA )," J. Ilm. Teknol. dan Inf. ASIA Malang, Stmik Asia Tinggi, Sekol. Inform. Manaj. Malang, vol. 8, no. 2, 2014.

[9] T. A. Arun, S. K. Arvin, and T. S. Madhukar, "Microcontroller Based DC Motor Speed Control Using PWM Technique," in Proceeding of The International Conference on Electrical, COmputer, and Telecomunication Engineering (ICECTE), 2015, no. December 2012.

[10] K. Ogata, Teknik Kontrol Automatik (Sistem Pengaturan). Jakarta: PT Erlangga, 1985.

[11] K. Ogata, Modern Control Engineering. New Jersey, USA: Prentice-Hall, 1997. 